\title{
NARRATIVIDAD, TESTIMONIOS ETNOGRÁFICOS Y HERMENÉUTICA EN LA OBRA DE CARMELO LISÓN
}

\author{
Narrativity, Ethnographic Testimonies and Hermeneutics \\ in the Work of Carmelo Lisón
}

\section{Narratividade, testemunhos etnográficos e bermenêutica na obra de Carmelo Lisón}

\author{
Enrique COUCEIRO DOMínguez \\ Universidade da Coruña \\ enrique.couceiro.dominguez@udc.es
}

Fecha de recepción: 3/10/2020

Fecha de aceptación: 23/02/2021

RESUMEN: De forma expresa y reiterada, Carmelo Lisón recalca la centralidad de la palabra y el oír en la investigación antropológica. En este terreno, su atención abarca desde la indagación hermenéutica de los campos semánticos de las «palabraspercha” a los relatos locales en torno a las aporías existenciales. No obstante, el discurso de sus monografías gallegas pone de manifiesto que en su quehacer etnográfico la vía visual también resulta decisiva para el registro de los episodios y, en ellos, para la cuidada creación de su narrativa textual. Esta pinza técnica que articula lo escuchado y lo observado es conforme con el método socio-hermenéutico característico de la antropología lisoniana, orientada a la comprensión e interpretación tentativa de los universos simbólicos de significados y valores culturales, incluidos sus aspectos más recónditos e inefables -lo que se vehicula a través del relato local-, pero siempre anclando la exégesis en una densa contextualización, sobre la roca sólida del análisis socio-estructural y ecológico de las condiciones reales de existencia de los colectivos humanos -lo que asimismo implica desarrollar una metódica perspectiva observadora-. En la elaboración de sus monografías, Lisón convoca una plétora etnográfica de fragmentos testimoniales en estilo directo que actúa como 
inicial hipotexto, cuya polifonía enriquece notablemente el hipertexto: su narrativa escrita de antropólogo-autor. Este es uno de los recursos del investigador que más sólida veracidad confieren a la ficción monográfica, al informarla con la experiencia local verbalizada. Se logra consolidar así, con eficacia inigualada, un género propiamente antropológico.

Palabras clave: Narratividad; hermenéutica antropológica; testimonios locales; diégesis.

ABSTRACT: In an express and repeated way, Carmelo Lisón emphasizes the centrality of the word and the hearing in anthropological research. In this area, his attention spans the hermeneutic indagation of the semantic fields of "words-perch" to local accounts around the existential aporia. However, the discourse of his Galician monographs shows that in his ethnographic work the visual pathway is also decisive for the recording of the episodes and, in them, for the careful creation of his textual narrative. This technical clamp that articulates the heard and the observed is in accordance with the socio-hermeneutic method characteristic of Lisonian anthropology, oriented to the understanding and tentative interpretation of the symbolic universes of cultural meanings and values, including its most remote and ineffable aspects -all of them vehiculated through the local narrative-, but always anchoring exegesis in a dense contextualization, on the solid rock of socio-structural and ecological analysis of the real existential conditions of human groups - which also involves developing a methodical observer perspective. In the elaboration of his monographs, Lisón convenes an ethnographic plettive of testimonial fragments in direct style that acts as an initial hypotext, whose polyphony remarkably enriches the hypertext; his narrative written as an anthropologist-author. This is one of the research's resources that more strong veracity confers on monographic fiction by informing it with local verbalized experience. In this way, an unequaled anthropological genre is thus consolidated.

Key words: Narrative; Anthropological hermeneutics; Local testimonies; Diegesis.

RESUMO: De forma expressa e reiterada, Carmelo Lisón reforça a centralidade da palavra y da escuta ne investigação antropológica. Neste terreno, sua atenção abrange desde a indagação hermenêutica dos campos semânticos das "palavras-chaves» aos relatos locais ao redor das aporias existenciais. No entanto, o discurso de suas monografias galegas destaca que em sua ocupação etnográfica a via visual também torna-se decisiva para o registro dos episódios e, neles, para a cuidada criação de sua narrativa textual. Esta pinça técnica que articula o escutado e o observado está de acordo com o método sócio hermenêutico característico da antropologia lisoniana, orientada a compreensão e interpretação tentativa dos universos simbólicos de significados e valores culturais, incluídos seus aspectos mais recônditos e inefáveis -o que é vincula através do relato local-, porém sempre ancorando a exegese numa densa contextualização, sobre a rocha sólida da análise sócio estrutural e ecológica das condições reais de existência dos coletivos humanos -o que assim 
mesmo implica desenvolver uma metódica perspectiva observadora-. Na elaboração de suas monografias, Lisón convoca uma abundância etnográfico de fragmentos testemunhais no estilo direto que atua como inicial hipotexto, cuja polifonia enriquece notavelmente o hipertexto; sua narrativa escrita de antropólogo-autor. Este é um dos recursos do investigador que mais solida veracidade conferem a ficção monográfica, ao informá-la com a experiência local verbalizada. Se consegue consolidar assim, com eficácia inigualada, um gênero propriamente antropológico.

Palavras-chave: Narratividade; hermenêutica antropológica; testemunhos locais; diégesis.

Parece obligado abrir unas reflexiones acerca de la narrativa en la obra de Carmelo Lisón, dejando constancia de su inequívoco reconocimiento de la centralidad de la palabra, el discurso oral, el relato y cuanto, estando lingüísticamente articulado, sea susceptible de audición en la investigación antropológica. Una palabra local registrada en la entrevista etnográfica grabada y en cualquier otro medio, comprendidos esos fragmentos de conversaciones casualmente escuchadas o informalmente mantenidas, rápidamente garrapateados en el cuaderno de campo. Pero en todo caso una palabra vertida a menudo en forma de relatos más o menos estructurados, que son los elementos de comunicación cultural que han ido labrando la comprensión del etnógrafo sobre los universos de representaciones y orden axiológico lugareños, así como su progresiva expertise personal en el reconocimiento de los usos locales del lenguaje, en función del contexto de conversación; cubriendo ahora funciones apelativas o conativas, después expresivas, referenciales o informativas, para saltar luego a propósitos mitopoiéticos, o fáticos. Una expertise morosamente proporcionada por la interacción dialógica mantenida en el tiempo, rutinaria, cuajada de ensayo y error; trabada de vaguedades interpretativas, sobreentendidos y contradicciones, y cotejada con la acción observada, que constituye el eje central del proceso etnográfico en campo y que pausadamente va proporcionando competencia para la comprensión del funcionamiento de vínculos, conflictos, alianzas, instituciones sociales y, sobre todo, de los usos de las palabras clave: símbolos dominantes que estructuran la cultura y comunicación locales.

I. LA RELATIVA PRIMACÍA DE LO OÍDO EN LA EMPRESA ETNOGRÁFICA: DE LAS PALABRASPERCHA A LAS NARRATIVAS

Parece inequívoca la primacía auditiva en la prospección etnográfica de Lisón, y su indicación de que en las palabras (aunque también en la actividad cotidiana y en el ritual) se encuentra la clave que franquea la comprensión de los mundos de representaciones culturales. Fundamentalmente porque el autor lo expresa reiteradamente en el inicio de publicaciones monográficas y teóricas 
que median entre sí varias décadas. Así, el prólogo de Brujería, estructura social y simbolismo en Galicia (1979), su monografía insignia sobre el tapiz de creencias y los especialistas taumatúrgicos de la Galicia de mediados del siglo XX -como después pasará a serlo, para mí, La Santa Compaña. Fantasías reales. Realidades fantásticas (2004) a propósito de la narrativa de la muerte y la trascendencia individual y colectiva-, lleva el siguiente encabezado:

En este que ahora presento ofrezco una muestra de mi personal convicción de que la investigación antropológico-cultural consiste fundamentalmente, aunque no exclusivamente, en oír. La receptividad y pasiva aceptación de significados y valores ajenos rima más con el arte de oír que con la activa facultad de ver. Guiado por las poéticas insinuaciones de Rilke he intentado que estuviera mi oído abierto a todo (...) Y lo que he escuchado han sido palabras; palabras con aroma, sabor e interioridad local: palabras con una poesía interna que en parte se nos escapa; palabras que en lenguaje técnico son conocidas como old-job-words (Wittgenstein), peg-words (Waisman) o covert concept (Whorf), esto es, palabras-percha de las que cuelgan numerosos, ambiguos y hasta contradictorios conceptos y funciones. En este volumen acaricio, manoseo cuidadosamente, con fruición, estas pocas palabras que tantas veces he oído en la ruralía gallega (1979: 7).

\section{Y en Teoría etnográfica de Galicia repite:}

En el trabajo de campo oímos, escuchamos atentamente a los informantes que dicen cosas y hablan de lo que conocen, creen y piensan: la etnografía local tiene que ser narrada para ser conocida. Y la narración obedece a dos tendencias principales de nuestra humana naturaleza; o bien describimos la realidad de la vida ordinaria (...) o bien referimos las ideas y creencias de un universo mental que crea mundos simbólicos, maravillosos, saturados de fantasía y fuerza creativa (2012: 67).

Es cierto que en los comienzos de la antropología lisoniana, la empresa interpretativa se centra en las citadas palabras-percha, y en el s. XXI el énfasis lo marca en el concepto de narratividad. Es una traslación del peso relativo de conceptos focales, probablemente consecuencia de la conmoción que en el pensamiento antropológico provocó, en el ínterin, la tendencia general de la disciplina a la revisión crítica de la construcción del texto antropológico, de sus narrativas y retóricas; o de la centralidad que la antropología presta a las posibilidades de abrir el texto a la polifonía y la heteroglosia de los protagonistas humanos de los fenómenos culturales reflejados, así como a la importancia del contexto dialógico y la reflexividad en la producción del sentido del discurso. Y Carmelo Lisón en todo momento se mantuvo críticamente vigilante de las tendencias emergentes en el panorama de la disciplina, llegando a adoptar y a articular en su método sociohermenéutico cuanto de eficazmente argumentado pudiesen estas aportar.

Aun así, el autor expresa no literal, pero sí inequívocamente, allá en la década de los setenta -en una época de general interés por la interpretación simbólica y el análisis estructural-, que de entre aquellas predilectas palabras-símbolo oídas la escucha se detuvo con particular atención (así, en Sobre antropología cognitiva: 
el arresponsador gallego - 1973) en las que conforman narraciones a la oscura luz invernal de la lareira; relatos de lances sobre el lobo, de apariciones de la estándiga o de sucesos brujescos. A propósito, es probable -y así lo sugiero aquí- que esta fascinación por las narraciones locales -tanto las que aluden a la herencia y a los conflictos puerta con puerta, como a las que lo hacen a las celebraciones vecinales, el cumplimiento de promesas o la compaña- haya estimulado la aproximación etnográfica y en el inquirir hermenéutico lisonianos también en parte debido, precisamente, al cultivo esmerado que aún hoy en la Galicia aldeana se hace del relato experiencial reposado (sea en primera o en tercera persona), pormenorizado en detalles locativos y cronológicos que emplazan los sucesos narrados, o en identidades y vínculos personales de los actores aludidos; aderezado de matices verosímiles del actuar de unos y otros, de ponderaciones éticas, de opiniones sobre lo que potencialmente pudo suceder, de analepsis aclaratorias, etc.; y debido por lo demás a la predilección que la población gallega siente por dicho relato. Un cultivo esmerado por los lugareños que se extiende a diversidad de temáticas narrativas -hoy bastante distintas de aquellas que protagonizaban los argumentos a mediados del s. XX-, revelando un particular disfrute estético y fático por el ars loquendi, por el relato ingeniosamente compuesto y estilosamente personalizado; colmado de claves y anclajes referenciales de realismo, pero también de hipérboles, divagaciones, exordios, intriga, ironía y dobles sentidos; valorado y preferido por la atención de la audiencia muy por encima de descripciones rápidas y lacónicas de generalidades. Una preferencia constatable casi en cualquier escenario coloquial. Habitualmente, hoy como ayer, la conversación en Galicia consiste en intercambios hilvanados, calmosos y disfrutados, casi celebrativamente, de tales narraciones.

En Brujería, estructura social y bermenéutica, cuatro de las "palabras percha» aludidas $-\mathrm{O}$ símbolos lingüísticos dominantes-, conceptos y personajes del panorama socio-ideático de la aldea gallega a los que Lisón presenta una atención central, la bruxa, o corpo aberto, a carteira y a sabia, son interpeladas antropológicamente rechazando de partida la tosca imputación de tratarse de «meras fantasías ridículas de pueblos tradicionales». Tanto en sus propias performances como personas reales en escenarios de curación -O a veces de conflicto vecinal-, como en las narraciones, descripciones y semblanzas, de tono temeroso, tal vez respetuoso, o acaso escéptico e irónico que de ellas hacen los paisanos informantes, esas categorías actúan en cambio como «signos o vehículos que nos trasportan a un mundo de emociones y abstracciones, de ecuaciones y símbolos, núcleo y esencia de la cultura local». La importancia simbólica y la relevancia semántica y moral de tan polisémicas categorías son de tal profundidad, potencia y ambiguas referencias, que apuntan directamente al núcleo mismo del balance de la sociabilidad y el Ethos, así como de la teoría aldeana de la causalidad del conflicto, la desgracia, la enfermedad, la salud e incluso la trascendencia preternatural de la persona o del vínculo parental. En correspondencia, los relatos de testimonio experiencial u opinión que tratan de las mismas, se encuentran culturalmente 
estandarizados -incluso podría decirse que a veces controlados con circunspección ritual, sin menoscabo de la diversidad léxica, idioléctica, valorativa y referencial con que son tratados- por ser comprometedores; y su tratamiento o alusión, como cajas de Pandora, comportar riesgo al asomarse a mundos insondables, a regiones tremendas de la realidad existencial.

Por tomar un ejemplo destacado, el capítulo dedicado a la bruxa hierve, como los restantes, de testimonios recolectados en torno al perfil profundamente enigmático, claro, oscuro e incierto de esta categoría -deslizando sus solapamientos semánticos hasta emerger a veces como carteira, acaso como la sabia, también en tanto que meiga o incluso aproximándose a la ambigua taumaturgia del cura-, taraceando el relato exegético que el autor labra de un fecundo contrapunto polifónico de fragmentos narrativos, recitados, fórmulas, etc. Algunos son episódicos, más reposadamente detallados (p.e, 1979: 158, 186-188, 210); otros, los más, ofrecen la sinergia de un aluvión de ejemplares fragmentarios, como en una página cualquiera donde convoca un total de 12 fragmentos testimoniales como los que siguen:

$\mathrm{Na}$ fonte das bruxas: alí hai moitos farrapos, e trapos vellos o vestidos vellos de persoas maiores. Alí van cando teñen enfermedades que non desaparecen o mala sorte na casa, co gando, o mal dollo (Quilmelas-Rairiz); bruxa dedicase a adivinaciones; se va a elas cando una persoa se sinte aflicta, o porque algunha cousa non le corre ben, o que lle pasa algo na vida (Rebordelo-Puente Caldelas); A Tina... le iba todo mal, se le morían los cerdos, las vacas...; llevó a una bruxa a su casa, le leía un libro [y] le bendijo las cuadras (Lugar de Bande); Las brujas a las que recurrimos mandan decir misas como remedios, dan herbajes, bendicen (Oya); Una meiga enmeiga, y entonces se iba a una bruja que con unas palabras y unos responsos que decía... lo [meigallo] destruía (El Barquero)... (1979: 174).

Muestras más infrecuentes de testimonios etnográficos las dedica a la recreación esporádica de algunos episodios completos y concretos de diálogo con estas personas «especialistas», culturalmente investidas de significación taumatúrgica y con aparición, mención y pertinencia característicamente enfocados en el orden de la vida vecinal, sea en la génesis de sus conflictos o su superación. La escasez de estas selectas descripciones más dilatadas resulta comprensible a efectos editoriales; pero son empleadas estratégicamente por Lisón, con vistas a ilustrar las ardides simbólico lingüísticas empleadas en las seances, en su alineación sintagmática -clave en la urdimbre lógica de la ejecución del acto-, y en su infinidad de matices de expresión y esgrima dialógica de la interacción entre investigador, especialista y "paciente" aldeano. Ahí el Maestro demuestra abiertamente una y otra vez cómo se conduce la mirada alerta, escrutadora, del investigador y el forcejeo dialéctico que emprende con la carteira, la corpo aberto o la bruxa, en pos de desentrañar los recursos y estratagemas de interrogatorio mediante los que esta experta sonsaca información a su clientela para así urdir sus designios etiológicooraculares y mistéricos diagnósticos sobre los causantes y causas de las desgracias 
que la aquejan; y para obrar, con diestro estimulo de la ilusión y de los «símbolos transaccionales» lingüísticos, el prodigio taumatúrgico mediante el cual provocar la metanoia, la conversión del cuitado a los argumentos y líneas interpretativas de su relato experto, de cara a impulsar el proceso de curación simbólica (Dow, 1986). Pero también Lisón emplea su arte interrogatorio (¡y con qué tensión!) para inquirir de la especialista, a su vez, sobre las convicciones acerca de sus decisiones, sobre los propios dones taumatúrgicos que tales mujeres asumen, e incluso incitarle a que formule destellos verbalizados sobre razonamientos -a veces pasmosamente profundos- tocantes a la causalidad y sus niveles, las posibilidades reales de la curación por la palabra, los potenciales espirituales, la reversión de la normalidad frente a la posesión, las relaciones humanas o la lógica de los modos místicos de sanación.

Por ejemplificar, el capítulo aludido sobre la bruxa lo concluye con una «breve galería de semblanzas» donde pormenoriza con detallismo descriptivo los prolegómenos, proceso y características contextuales de tres selectos encuentros con bruxas y uno con un bruxo que se dedican a sanar a aquejados de enfermedades e infortunios. Los presenta como

....unos pocos bosquejos personales de algunos de estos intérpretes místicos y traductores poéticos de la enfermedad; son algo así como pinceladas para colorear el cuadro que he intentado dibujar. He esperado muchas veces a sus puertas y entrado a sus consultas con mente abierta. He aquí un mínimo retazo de mi amplia experiencia (1979: 234).

Lo cierto es que, en la presentación de cada caso, llama la atención el papel dinámico y ubicuo de los detalles derivados de la pura observación -incluidos los comentarios de diversos actores, como hechos de observación per se- o de inferencias fugaces y tentativas derivadas de la misma, como tercera persona que examina la situación con la cuasi-pasividad de la escucha etnográfica, y da cuenta de ella. Esto nos revela, en primer término, que en la etnografía de Lisón la vía visual es, de hecho, considerablemente decisiva en el registro de los episodios -y en ellos, por tanto, también en la elaborada creación de la narración autoral impresa-, incluso a la escala del relato extenso de cada caso ejemplificador. Este canal observacional se entrevera, no obstante, con elementos descriptivos cuya procedencia -como se infiere obviamente-solo puede haberse derivado de uno $\mathrm{u}$ otro acto previo de diálogo del investigador con la persona o personas esbozadas. Un ejemplo cualquiera de la excepcional densidad e intensidad observadora es este pasaje de uno de los casos (las cursivas son mías).

Uno de los cuatro que anteriormente había estado con los demás en la consulta vuelve a entrar. Es un mozo alto, moreno, bien vestido, que no pasa de los veinticinco, emigrado y residente en Venezuela, pero que durante las vacaciones veraniegas va con su coche a los numerosos lugares en fiesta o romería. Me reconoce por haberme visto filmar en Sabucedo. Se sienta en el banquillo, se acerca a la bruja y, como en confesión, le habla al oído. Sigue un corto diálogo del que es imposible 
oír nada, y comienza a bendecirle con las numerosas cruces propias de su ritual. De repente, cuando le está haciendo una cruz sobre el pecho, se estremece el enfermo, gime y se echa convulsivamente para atrás. Este movimiento de rechazo es similar, y me hace inmediatamente recordar al de aquellos que se creen endemoniados, al ponerlos en contacto con un objeto sagrado. En este momento la hija [de la bruja] que está conmigo a la puerta, aprecia que yo sigo con mucha mayor atención la actividad de dentro que lo que ella me cuenta, cierra despacio y casi totalmente la puerta, asegurándome que se trata de un joven que no querrá que le vean; pero la puerta se comienza a abrir sola, imperceptiblemente. Al salir le da dinero y se marcha con los compañeros (1979: 235-236).

Llamo la atención con este caso, sobre cómo en ocasiones, aun paradójicamente, la intensa atención observadora (usualmente conjugada con una actitud muy contenida del investigador en su papel intradiegéticamente presentado, con que trata de resaltar el protagonismo concedido en la escena a los actores locales) llega a superar el cuidado prestado al diálogo directamente mantenido, por más que generalmente y de forma fluida, visión y audición se articulen en complementariedad, y en contraste contrapuntístico. En cierto modo, esta constatación relativiza la apelación lisoniana al predominio de la palabra: sin embargo, tal relativización creo que ya estaba perfectamente dada por hecho en el programa de Lisón. Y es que si algo recuerdo característico de lo más fundamental de su aproximación a los fenómenos culturales estudiados es su permanente voto por la conjunción a la hora de captar y valorar distintos alcances semánticos y efectivos para luego ensayar su articulación interpretativa; pero relegando a un nivel notablemente secundario el recurso a la disyunción excluyente y categórica. Y no sólo para estar abierto a captar la polisemia y presto a atrapar y registrar, para la exitosa penetración hermenéutica de la condensación, la sustantiva y escurridiza ambigüedad y ambivalencia de los fenómenos de simbolismo cultural en cualquier práctica, enunciado o gesto. Se trata de un voto decidido por la conjunción, asimismo, en el plano metodológico: ya se cuida el autor, más allá de recalcar la primacía del «oír» el relato en la empresa etnográfica, de hacerlo «aunque no exclusivamente»; de dar la debida acogida en la panoplia técnica también a la mirada del comportamiento objetivo y, con este, del condicionamiento ecológico, social e histórico de la forma y sentidos de lo dicho. Pero se trata de un hábito conjuntivo que sigue también cuando aborda el análisis interpretativo de la experiencia humana articulando inclusivamente en su humanismo hermenéutico la cimentación socio-estructural $y$ cultural de las creaciones del espíritu.

\section{ESQUEMAS CULTURALES Y ESTILO IDIOLÉCTICO EN LA CONSTITUCIÓN NARRATIVA DE LA EXPERIENCIA PERSONAL}

Volviendo al análisis fenomenológico de la narración, se advierte que este nos muestra, en primer lugar, 
el carácter lingüístico de la experiencia, pero juntamente e inseparable de detalles, hechos y episodios; son precisamente estos los que nos liberan tanto de la cárcel de la sintaxis, como de la danza de principios abstractos (2012: 177).

En mi opinión, aquí incide Lisón sobre la necesidad de reconocer la naturaleza dialéctica de una experiencia necesariamente configurada en modo narrativo para que cobre efectividad concebible y comunicable como tal. Realidad dialéctica en cuanto que, de un lado, resulta formalizada según esquemas culturales y narrativos, como condición para convertirse en representación organizada, inteligible, asumible y coloquialmente explicitable; y de otro lado, se desarrolla desde una vivencia personal particular, agencialmente desplegada, del acontecimiento que es narrado como experiencia; vivencia íntima que aporta singularidad a un relato por lo demás estandarizado ipso facto por los citados esquemas narrativos compartidos.

El interés lisoniano por primar en el análisis de los relatos locales su composición sobre la base de esquemas narrativos colectivos, interiorizados por enculturación y anclados en más fundamentales patterns culturales, se expresa a mi parecer con particular efectividad sintética en la primera parte del estudio Sobre antropología cognitiva: el arresponsador gallego (1981): concretamente cuando "descubre» en sus testimonios camperos la asombrosa homogeneidad formal de los relatos acerca de la aparición y ataque del lobo obtenidos de aldeanos que vivieron esa experiencia. Esos esquemas narrativos interiorizados por el relator no sólo convierten las experiencias personales -y más las que tienen que ver con las regiones de lo desconocido, de lo salvaje, de las ultimidades existenciales, de lo numinoso y de lo extraordinario- en vívidas narrativas comunicables y en mayor o menor medida plausibles, sino que incluso constituyen, bajo forma de auto-relato, tal experiencia como concebible en la conciencia del propio yo homodiegético y relator del protagonista de la experiencia ${ }^{1}$ :

Desde el momento en que todos describen la sensación de la experiencia [del encuentro con el lobo] de idéntica forma, estamos de nuevo ante la aprehensión no de una situación objetiva, sino de notas o atributos culturales (...) [como representación y evaluación culturales] el folklore del lobo pone, ordena los data; entre ellos es más inmediata y real la cultura lobezna que el lobo animal (1981: 130-132).

Los esquemas narrativos se interiorizan por socialización en el estilo conversacional y en la cosmovisión del medio cultural donde la persona se mueve, comunica y convive; los detalles, hechos y episodios corresponden al juego de condicionantes, elementos, lugares y tiempos específicos de la vivencia personal y privativa experimentada por el narrador en su pasado; pero también a su idiolecto expresivo -en el cual cuenta su personal imaginación y habilidad con la pirotecnia

1. Trato el tema de estos esquemas narrativos y sus transformaciones en los últimos cincuenta años en COUCEIRO, 2020. 
retórica-, y sobre todo al cambiante escenario conversacional donde emite la narración. Además, como apunta oportunamente Lisón, la repetición del relato en momentos más distantes de la experiencia vivida, dota "de significado y sentido a aquella pasada escena personal partiendo de una interpretación presente [de la misma]", con lo que en los relatos regidos por esquemas narrativos específicos (operando en ellos los esquemas culturales de la experiencia), podemos llegar a «... conocer directamente aspectos del presente cuando narran $-\mathrm{O}$ indagando- dimensiones del pasado. La trasposición de tiempos -vivido, pensado y presenteservirá más delante de esquema ordenador e interpretativo» (1981: 133).

Por esta razón, trasposición temporal, idiolecto y contexto de situación (especialmente el momento y la audiencia ante quien se narra) siempre implican variaciones que fuerzan, trastocan y en parte innovan y resignifican las formas pautadas del esquema narrativo al uso sobre el tema tratado, constituyendo así vectores liberatorios de determinaciones formales, cristalizadoras de la realidad singular de esa experiencia.

Sin embargo, y en segundo lugar, en nuestro nivel de comprensión como investigadores externos a la esfera vivencial local, las palabras del narrador, dueño a la postre de una experiencia privativa y de las claves del texto oral que da cuenta de ella, son insuficientes, ya que

no descifran ni explican, presentan el misterio de la aparición nocturna [se refiere ahora a su estudio de la compañan] que requiere contextualización e historicidad. Y ambas requieren descripción exhaustiva externa porque los objetos, las personas, las acciones y el comportamiento sobrepasan la presencia y mediación de la lengua (2012: 177).

\section{CONTEXTUalización SOciocultural y VERSTEHEN ANTROPOlÓGicA}

Aquí aflora un requisito metodológico lisoniano clave: la básica y precisa contextualización propiamente antropológico-social -o estructural- de las manifestaciones culturales, y en ellas de las narrativas. Se trata de una fase analítica del procedimiento que entronca con la resuelta fundamentación socio-estructural de las investigaciones de Leach, Douglas, Lienhardt, Evans-Pritchard, y que refleja una convergencia con Turner, en el énfasis que este hace de la importancia clave del análisis de los «contextos significativos en gran parte elaborados por el antropólogo» (Turner, 1999: 22) sobre los resultados registrados de la exégesis verbal nativa, ya que,

(...) el antropólogo, que previamente ha hecho un análisis estructural de la sociedad (...), que ha aislado los principios de su organización, que ha distinguido sus grupos y sus relaciones, no tiene prejuicios particulares y puede observar las interconexiones y los conflictos reales entre personas y grupos, y la medida en que reciben representación ritual (2012: 30). 
Turner privilegia explícitamente la interpretación antropológica sobre la exégesis nativa, porque el investigador puede colocar el ritual en el marco de su campo significante y describir la estructura y propiedades sociológicas, ecológicas y culturales de ese campo; y porque la visión del nativo se ve limitada al estar anclada a su propia y reducida perspectiva estructural, y sujeta a «intereses, propósitos y sentimientos dependientes de su propia visión específica que obstaculicen su comprensión de la situación total» (Turner, 2012: 29). En este sentido, es cierto que Lisón subraya la importancia del análisis estructural en referencia particular a las palabras-símbolo y las narrativas, y Turner respecto al simbolismo ritual; y es posible que las diferentes características de uno y otro modo de comunicación -oralidad vs. acción pautada- hayan estimulado en uno y otro caso matices metodológicos diferenciales (añadidos a los que ya aporta de por si la fuerte impronta diltheyana de la hermenéutica de Lisón) ${ }^{2}$.

Lisón también insiste en la necesidad de que la exégesis antropológica trascienda el puro nivel referencial del dictum del narrador, de su textualidad acondicionada de maniobras retóricas y comunicación no verbal, contemplándolo inquisitivamente a la luz del registro etnográfico de condicionantes y posibilidades vinculativas, y del rigor de las condiciones materiales de la existencia de las personas. Pero nuestro autor no considera "limitada" la interpretación nativa en cuanto a su sobrada pertinencia lógica dentro de la esfera del Ethos, Weltanschauung y Pathos preponderantes en el propio entorno del narrador: muy al contrario, le reconoce superior competencia en el manejo y usos prácticos de sus relatos y campos referenciales, en la evaluación de sus sentidos, intenciones e implicata. Ahora bien, también subraya en dicha interpretación nativa la existencia de limitaciones, de cara a una comprensión antropológica, externa, de las humanas inquietudes y sentidos locales, pues «las palabras no descifran ni explican, presentan el misterio de la aparición nocturna que requiere contextualización e historicidad» (Lisón, 2012: 177). Aquí, Lisón advierte que una significativa limitación se encuentra también en el propio antropólogo: en la imposibilidad de que este alcance, a la postre, una "empatía plenamente mimética», que capacite para plasmar y dar cuenta íntegra de la abundancia de implicaciones emotivas, morales, cognitivas o estratégicas de la experiencia narrada tal y como son percibidas por el narrador que las viviera en primera persona, quien es un verdadero maestro en las mismas. Tampoco el antropólogo es quien de ir mucho más allá de la comprensión de la intentio operis de la narración local por la precaria vía de complementarla con la elusiva intentio auctoris, que sólo está plenamente de la mano de su interlocutor

2. Fundamentalmente en el sentido de la hermenéutica como vía de interpretación de las manifestaciones del espíritu expresadas en signos y referidas a las vivencias: la base de esta empresa hermenéutica será la comprensión, la Versteben, y no la explicación. Esta comprensión resultará un movimiento clave que posibilita captar el mundo del espíritu desplegado en exteriorizaciones objetivas, contemplando al hombre como configurador de la cultura, pero sin dejar recíprocamente de ser parte de ella. El significado resulta, desde este ángulo, intrínseco a la vida. 
autóctono. Por ello, previene lo siguiente, en referencia a la divergencia cognitiva y funcional entre narrador y etnógrafo, en el contexto dialógico de la labor etnográfica, y sobre el ejemplo de su indagación de la narrativa de la compaña (las cursivas son mías):

(...) los enunciados epifánicos de realidad en primera persona no se distinguen en forma de una descripción (...), pero hay una tirantez entre el nivel de decir y la inteligibilidad, porque, aunque el etnógrafo habita también en el mundo narrativo no capta en su riqueza la experiencia místico-emotiva, deslumbrante, del visionario ni penetra ese intermundo nocturno, por lo que tiene que energetizarlo con inyecciones de significado (2006: 177).

Es decir, a pesar de todo, esa limitación no impide la Verstehen antropológica, pues para ello, -y valga la paradoja implícita- la narrativa analítico-interpretativa, propia del discurso del nivel antropológico del proceso, procura reconocer sus niveles de significación, y las vinculaciones analógicas de sentido entre los mismos, a base de distanciarse de la narrativa local para situarla en perspectiva, en su contexto sociocultural más que -o por añadidura a- su inmediato contexto de situación. Suspende la mera escucha de lo relatado para observar con la mirada de la razón el encaje, desencaje o deslizamientos de lo dicho sobre el tapiz de personales, exteriores y sistemáticas observaciones -y audiciones- etnográficas de los contextos. En ello, esta vez converge con Geertz (2007) en el recurso a la descripción densa de los contextos concurrentes. Por ello apercibe vivamente de la necesidad de ir más allá del relato para afianzar la interpretación en el sólido y sistemático andamiaje de inferencias sobre la realidad social y material que siempre subyace a la experiencia y la actividad humanas:

Los fenómenos sociales existen no sólo en la dicción y en nuestras mentes, sino en el mundo objetivo y empírico en el que encontramos relaciones e instituciones razonablemente estables, regularidades y secuencias temporales que van más allá del individuo (Geertz, 2007: 177).

La realidad, entendida aquí por la dimensión objetiva de lo existente, lo «que está ahí afuera", es inherente al mundo, e inmanente:

(...) viene, por tanto, vehiculada y confirmada por las vidas de los individuos, en la praxis humana y en el contexto del mundo material, hontanar de verdad. Acción y dicción en interacción, narración más comportamiento externo, lengua más sucesos reales en un mundo real, el mundo fuera del texto (...) inserción en la historicidad y unidad con la época son, entre otras, las claves sobreimpuestas a la narratología para fundamentar en roca dura el análisis antropológico (Geertz, 2007: 177-178).

Con esta crucial apreciación metodológica, socio-hermenéutica, de la doble base verbal y fáctica del reconocimiento etnográfico y de la reflexión antropológica en la captación, comprensión e interpretación de sentidos locales y universales, Lisón, por un lado, apuesta irrenunciablemente por lo escuchado y por lo visto; y 
empleando esta tenaza metodológica se desmarca, a la par que de la perspectiva positivista, de otra nativista: rechaza rastrear sentidos concediendo simplemente prioridad y suficiencia a la exégesis consciente del relator local. Ello alude a una vieja controversia antropológico social, en la que por ejemplo Nadel (2020[1954]), adoptando una tendencia próxima a tales posiciones nativistas -aunque persiguiendo un interés de análisis estructural-, daba primacía a la validez del punto de vista expreso del informante local en la exégesis simbólica, y defendía que los símbolos no comprendidos por quienes hacen uso de ellos son irrelevantes para la investigación social, pues si su efectividad social radica en su capacidad para indicar, la carencia de ésta los descarta como fenómenos antropológicamente significativos, e incluso como símbolos ${ }^{3}$.

\section{GÉNERO NARRATIVO Y GÉNERO ANTROPOLÓGICO: POLIFONÍA E HIPERTEXTUALIZACIÓN EN LA CONSTRUCCIÓN DE LA NARRACIÓN ESCRITA}

Sin embargo, el método de Lisón conlleva un deslizamiento gradual, no categórico, aunque tenso y tentativo, desde la narración local dialógicamente mantenida (que, recogida o recordada, actúe como inicial hipotexto), experimentada en sus formas y sentidos por narrador y audiencia, hasta su hipertextualización o intertextualización antropológica, de un modo que preserva la emicidad, y en parte la subjetividad inherentes a aquella pero a la par permite la inferencia generalizadora y el edificio teórico:

Ambos, investigador y visionario, asumen que la experiencia es reina (...) los dos están convencidos de que todo fluye de lo real (...) facilita la empatía etnográfica con el vidente el hecho de que ambos parten de una intensa percepción del paisaje físico y moral y de que ambos reproducen el mundo circundante comunitario (...) el genre narrativo y el genre etnográfico son inseparables; sus voces son nuestros textos iniciales. (...) Hay una tensión dialéctica continua entre el narrador con su análisis y focalización internos, el etnógrafo que procura extraer la universalidad de su

3. Agregar otra nota a pie de página con el siguiente texto:

Igualmente, Mónica Wilson, como señala Turner, apuesta abiertamente por la suficiencia de la interpretación nativa. Wilson (1954) declara en relación a la interpretación del simbolismo ritual Nyakiusa, e implicando las reticencias hacia exégesis foráneas (las cursivas son mías):

"El análisis ofrecido aquí se basa en la interpretación Nyakyusa de los símbolos. Tuvimos suerte, entre los Nyakyusa, al encontrar personas que pudieran y quisieran interpretar la mayoría de los símbolos que se producían en los rituales, y sus interpretaciones entraban en un acuerdo sustancial. Parecía, a partir de la evidencia encajada, que ciertos símbolos eran entendidos por todo el mundo, por ejemplo, una variedad de lantain, itoki, representa a un hombre, y el iselya, un plátano dulce comido maduro, representa a una mujer, y este simbolismo es tan sencillo para los Nyakyusa como los pantalones y "petticoats" son para nosotros; otros símbolos fueron entendidos sólo por algunas personas. Los más conscientes de ellos eran sacerdotes y médicos: Kasitile, hacedor de lluvias hereditario y un anciano, era nuestro mejor informante sobre estos asuntos, pero había una docena de otros casi tan buenos». 
singular experiencia campera y el antropólogo hermeneuta que, en riguroso análisis externo y proposicional, interpreta teoréticamente (Lisón, 2006: 176).

Por otro lado, con el anclaje de las narraciones y sus exégesis locales en «la roca dura" del análisis de la realidad social y ecológica inmanente a la vida local, Lisón sale al paso de algunas impugnaciones postestructuralistas a la validez de proceso y producto antropológicos. Descarta que estos puedan ser confundidos con la mera ficción literaria libre o arbitrariamente entretejida por la imaginación autoral con los mimbres de su solo impulso figurativo, de un status privilegiado sobre los informantes y de unas experiencias relatadas, compartidas, y luego, en la hipertextualización monográfica, saqueadas y deturpadas respecto a esos relatores primeros, a sus contextos e intenciones (cf. Clifford y Marcus, 1991). Es así que la narrativa compuesta, esta vez, por el investigador, se fundamenta también en una perspectiva externa de análisis socio-estructural, verificada con «severidad y refinamiento analítico, facultad crítico-hermenéutica y otro modo [el antropológico] de representación" (Lisón, 2006: 178). Esta labor es papel privativo del investigador, al ser referente básico e irrenunciable de su Verstehen y hermenéutica de las semánticas culturales; papel materializado en la progresiva -y siempre tentativa, abierta- transcripción etnográfica de relatos orales e inscripción de los mismos en el nuevo y "externo» edificio narrativo del texto antropológico. Ello le exige no renunciar a un papel autoral activamente protagonista, ni a su punto de vista inferencial, exegético, comparativo y reflexivo; pero también comporta, como señalé, preservar dignamente, en la medida de lo posible, la subjetividad de los individuos narradores, a través de la presentación de sus palabras en estilo directo y dando cuenta de su singularidad y diversidad, al menos como categorías humanas, a lo largo de los ejes territorial y sociológico y con la dificultad que supone convocar una miríada de ellos, como interlocutores con escuetas entradas, en las páginas de cada volumen de la serie de Antropología social de Galicia. La espesura polifónica así lograda, en fundamento y apoyo etnográfico-comparativo de la determinación de sus variantes "coordenadas semántico-semióticas" y los sentidos de sus narrativas -en parte privativos, en parte estandarizados mediante esquemas culturales y palabras-símbolo-, consiste en una constelación de experiencias y opiniones narradas casi siempre fragmentarias y con función ejemplificadora de la argumentación autoral, aunque también la maticen y provoquen un desbordamiento polisémico de los límites de esta, e incluso la ambiguación de lo que el antropólogo sugiere. La fragmentariedad que de facto sólo alcanza a insinuar en escorzo subjetividades y creatividad de los informantes, apenas puede atenuarse; pero es la contrapartida que impone la apuesta por la inmensa pluralidad de puntos de vista textualmente emplazados, salvo cuando el autor se detiene con deleitada parsimonia en esas contadas y magistrales semblanzas etnográficas que privilegian los diálogos mantenidos con determinadas "Sabias", "bruxas" O "carteiras» particularmente destacadas en su periplo campero. No obstante, la constelación de miles de fragmentos narrativos resplandece con una sinergia, en conjunto, 
portentosa, imponente y -creo- inigualable en su vastedad temática y geográfica, en sus matizaciones tipológicas, en el alcance de su prolijidad estilística, lingüística y contrastativa, o en la casi insondable trascendencia de sus connotaciones humanas y espirituales. Y aunque tal polifonía de "fragmentos testimoniales en estilo directo» constituya asimismo un recurso poderoso y esencial de la estrategia retórica de la narrativa escrita lisoniana, "el espesor y complejidad de la voz local es simplemente imprescindible en nuestra tarea y la estrategia narrativo-textual parte de nuestra metodología» (Lisón, 2006: 172-173).

El caso es que, fundamentándose en el método estructural, descubriendo los patterns que ilustran los principios organizativos de la fenomenología cultural (del hacer taumatúrgico de la corpo aberto, del relato de la aparición del lobo o del de la vislumbre de la estadea) que, en forma de esquemas culturales y manejo de palabras clave, informan y semantizan el mundo mental, se investiga "lo cultural en lo social y la inserción privativa de éste en aquél. De esta forma pretendemos integrar narración, sociedad y cultura, socializar la narración y narrativizar la cultura» (Lisón, 2012: 178). Lisón gusta en sus textos de destacar una suerte de "tanto monta" de lo social y lo cultural, cada uno en su plano de manifestación fenomenológica, como esferas formalmente discernibles de la condición humana colectiva, abordables desde distintos niveles analíticos pero con una indisociable articulación en la realidad, cuya indagación exige atender tanto a las caballerías de la palabra narrada y el rito (estratégicamente en el nivel cultural), como a la montura de la atenta observación in situ (principalmente en el nivel del comportamiento social) para el sustento y composición de la narrativa textual propiamente antropológica. Las relaciones vecinales o entre parientes subyacen a lo narrado; y lo narrado da expresión formal y personal a los contenidos y alcances de significado de la cultura en los terrenos de la herencia, la celebración sanjuanera, la explicación de la desgracia, etc. Es encajando combinatoriamente estos contrapuntos como se va componiendo la narrativa antropológica escrita en su carácter textual e intertextual -pues parte de, e instrumentaliza, relatos o «textos orales» de origen local-, en pos del análisis social y tras él de la cultura espiritual. Una narrativa antropológica parcialmente homologada (pues comparte recursos retóricos) a las narrativas locales, a la par que diferenciada de las mismas. Con sencillez sintetiza esta idea en el siguiente pasaje de De antropológica narratione (Lisón, 2006: 172):

Los informantes actúan unas veces como vehículos representativos de información (...) nos percatamos ciertamente de cómo seleccionan, añaden, excluyen, metaforizan y retorizan (...) pero otras informan en grado mayor y sorprendente al transportarnos a un mundo mirífico y misterioso y a un discurso con lógica peculiar. Actúan como sujetos autónomos, independientes en su narración, cuya gramática y sintaxis tenemos primero que aprender, para establecer un diálogo pertinente después. En ambos casos partimos -aunque no exclusivamente- de la narración para alcanzar la estructura social en el primero y la del espiritu en el segundo; vertemos sus palabras en textos cuyos elementos y partes seleccionamos, subrayamos y disponemos en perspectiva retórica convincente -como ellos-, que presentamos en una 
gran narrativa, en una monografía. Con las mismas piedras nobles levantamos un edificio, pero con otro diseño: somos ficcioneros (...) pero reforzamos la estabilidad de la arquitectura con una severa crítica de las condiciones materiales de existencia de los fenómenos, para que nuestros pequeños monumentos narrativos descansen en roca dura y sean algo más que realidad puramente narrada. (...) lo que pretendo indicar (...) es la imbricación, similaridad y diferencias entre el modo lingüístico narrativo y el modo etnográfico-antropológico.

\section{LOS RELATOS MITO-POIÉTICOS LOCALES Y SU EXIGENCIA DE OTRA HERMENÉUTICA ANTROPOLÓGICA}

Con todo, la empresa interpretativa no acaba ahí, sino que sobre ese fundamento la pesquisa antropológica continúa ruta transitando, en un postrer escalón, de lo específico representativo a lo universal panhumano. La contextualización y triangulación socio-narrativo-cultural permitió conjuntar episodios, vínculos, categorías, argumentos, relatos, incidentes y acciones en una configuración total que nos permite inferir el sentido de la vida y acontecer del colectivo humano; de sus esquemas, procesos, problemas, ejes de fricción y orientaciones axiológicas, emotivas y cognitivas. Pero ahí no se agota el potencial de sentido del relato, pues la narración local es "inherentemente polívoca», vehículo de múltiples planos de significado, algunos de los cuales proyectan la atención hacia destinos mucho más allá de lo cotidiano y mundano. Particularmente cuando se trata de esas formas sublimes de la narrativa que son el mito, la leyenda, la parábola, o la creencia religiosa tan febrilmente prospectados por la indagación antropológica y ávidamente sondeados por el genio hermenéutico de Lisón ${ }^{4}$, especial y excelentemente en ese motivo mítico gallego que es el relato de la compaña en sus versiones y denominaciones comarcales (estadea, hostilla, estantigua, estándiga, as da noite, etc.). Son singulares creaciones narrativas, productos de la imaginación mito-poiética, que el ser humano dondequiera, siempre en formas culturalmente tipificadas, despliega para afrontar lo mistérico; los mundos metafísicos y de esencias; las aporías de la condición humana, de forma que tentativamente y con incertidumbre narrativa, pero también valiéndose de esquema narrativo y panoplia de figuraciones simbólicas culturalmente estandarizadas, tratan de escrutar lo insondable, de explicar lo inexplicable, de dar encaje al prodigio, de conjeturar con imágenes la posibilidad de lo empíricamente imposible. Son los relatos que escudriñan la hiperrealidad más real que lo ordinariamente real y exponen lo inefable; de ahí su impulso metanarrativo: grandes relatos urdidos con recatados y aldeanos -aunque

4. Carmelo Lisón lo aborda una y otra vez a lo largo su obra. Destaco aquí los que para mí son lugares sobresalientes: Brujería, estructura social y suimbolismo en Galicia (1979); La España Mental II: Endemoniados en Galicia, boy; La Santa Compaña. Fantasias reales. Realidades fantásticas (2004), y con un tratamiento sintético y teórico en Teoría etnográfica de Galicia (2012), y "De antropológica narratione» (2006). 
tremendamente dramáticos- mimbres imaginario-expresivos que apuntan a ultimidades de la existencia (el poder temible de la meiga; la capacidad mediúmnica del corpo aberto; la efectividad abogosa, aunada a la capacidad punitiva del Santo; la pertinacia de la enfermedad y el portento taumatúrgico de la sanación por la sabia; la fatal recurrencia de la desgracia y la muerte, pero también la trascendencia; la conquista de la fertilidad (mediante el bautismo prenatal); el origen de los elementos del paisaje, la determinación de los antepasados de la humanidad actual en el tema de los mouros u os antigos...). Así perfila Lisón en Teoría etnográfica de Galicia esta audacia narrativa del asalto poiético de lo mistéricamente inaccesible:

La provocación por la palabra -anacrusis- va todavía más allá: su llamada a lo maravilloso, extraño, distante y misterioso más su sobreintencionalidad franquean este metafísico universo para ponernos en comunicación con lo inefable; la fuerza elemental del lenguaje axiológico y creencial y la dinamicidad de su potencial configuran un mundo tanto ideal como preternatural -según los casos- de realidad y verdad con significado total tanto entre ellos como entre nosotros (Lisón, 2012: 71).

Para la culminación del periplo antropológico entre el Olimpo y el Hades de la condición humana, Lisón advierte, entonces, que es precisa otra hermenéutica que parta de focalizar la narración «como verdadera poiesis en su carácter exclusivamente expresivo-poiético». Lógicamente se refiere a los relatos formalmente mitificados sobre experiencias de la aparición de la compaña, -o de la interacción con la bruxa, o de la posesión por el espirito del familiar difunto-, incluso cuando el protagonista actúe, según el caso, homodiegéticamente dentro de ellos. Y es precisa esa focalización exclusiva -más allá de escenarios sociológicos- en la libertad creativa del espíritu que anima la narración, porque ésta (1) nos aboca a un ámbito de incertidumbre "poblado de semas multivalentes y huidizos y por significantes alegórico-mágicos» (Lisón, 2006: 179-180); (2) desborda de significados sugeridos, muchos de ellos ilógicos, amagados e inacabados, que permiten el sobresentido metanarrativo referido a la muerte, a la efectividad de la taumaturgia, o a la trascendencia allende las esquinas de este mundo; (3) sin desaparecer de la esfera de la creencia, esta creación poética se resiste al encorsetamiento textual de modo que la palabra y el significado concreto del relato no llegan a traducirla, a dar cuenta de ella, sino a evocarla veladamente; y (4) se narran aporías, extremos existenciales que los narradores no entienden, pero que nadie puede ignorar: el no entender les fuerza a figurar lo hablado. Por tanto, la narración mítica deviene válida en sí misma: revela y proclama sin explicar ni admitir comprobación de lo dicho. Se trata de una forma de experiencia humana que a pesar de la ambigüedad e incertidumbre en torno a lo que narra, constituye una respuesta acreditada y no una pregunta; una experiencia cuyo solo puente -tanto para el narrador y su audiencia local como para el intérprete- es la palabra narrativa: "el sentido inmanentemente creador de la palabra crea el orden del espíritu y manifiesta estados de alma» (Lisón, 2012: 71). Narraciones, en suma, de carácter apodíctico, 
arraigadas en la general vivencia de los eternos arcanos de las ultimidades de la realidad humana de los que dan cuenta, y de las que la reflexión y la explicación de los acontecimientos parten; pero narraciones a las que éstas últimas no desencantan ni afectan críticamente, al menos durante los tiempos de su vigorosa juventud cultural, cuando su impresionante verdad se halla en sus propios términos naturalizada, e informa el sentido común a despecho de la irracionalidad de las experiencias que describen -difícilmente podemos decir hoy esto de la estadea-. Y no obstante el carácter poiético-lingüístico de estos mundos trascendentes, Lisón nos recuerda abruptamente, de nuevo, que la raigambre en la realidad de esta fenomenología narrativa nos obliga a comprobar el anclaje de la interpretación imaginativa y sutil que de ella hagamos en aquellas estructuras sociales y materiales, valores y nociones que hemos analizado etnográficamente sobre el terreno:

Todo pasa por la palabra. Pero lo fascinante antropológicamente es que ese mundo místico e inmaterial tiene firmes soportes materiales, formas de actualización, enunciados de realidad y moralizadores de verdad. Nuestra filosofía humanística es empírica (Lisón, 2012: 71).

De cualquier modo, también esta ulterior y cimera fase hermenéutica del proceso antropológico presenta aspectos susceptibles de debate, en común con la fase de la etnografía y examen sociocultural que, como vimos, colecta y emplaza los relatos locales.

Para empezar, el relator de la experiencia extraordinaria es posible que sí entienda la trayectoria y alcance semántico-existenciales de la misma, y perciba sus asociaciones connotadas, aun cuando su comunicación le fuerce a recurrir a la expresión figurativa. Esta comprensión no es ciertamente idéntica a la que está en el germen de la interpretación del antropólogo, reafirmada e informada en el manejo de la contextualización sociocultural y de la comparación de regularidades panhumanas, que acaso otorguen a éste cierta ventaja a modo de kataskopos: como «el espía que mira penetrantemente»... entreviendo una cartografía de sentido global. Pero la brecha entre informante-narrador y antropólogo-intérprete a menudo se magnifica y distorsiona como resultado vicioso de la escritura del texto monográfico, pues en campo -sobreentendidos y malentendidos aparte- la comprensión de lo dicho y su accesibilidad están en juego y tratan de cultivarse y compartirse en el proceso mismo del diálogo etnográfico desde todas las bandas, admitiendo con ello que los hechos culturales recogidos (otra cosa es lo que ocurra con los hipertextualizados en la monografía publicada) tienen mucho de creaciones concertadas en el curso de una relación fronteriza dialógica e intercultural (Rabinow, 1992). Esa corresponsabilidad en la activación del acontecimiento narrativo y su inserción en un continuo de comunicación, más allá de las asimetrías y diferencias culturales entre relator y oyente, es algo a lo que también apunta Georges (1969: 313-328):

...dado que los acontecimientos narrativos son eventos comunicativos y experiencias sociales, pueden ser generados por las interacciones de dos o más personas 
independientemente de sus estados sociales, económicos o educativos. (...) porque los acontecimientos narrativos constituyen un tipo de evento comunicativo dentro de la comunicación humana continua y un tipo de experiencia social dentro de la red de interrelaciones sociales entre las personas, independientemente de sus estados sociales, educativos o económicos relativos.

Y aún con las grandes dudas e incertidumbre que puedan embargar al narrador aldeano, su entendimiento de las implicaciones de significado de lo narrado, incluso en sus aspectos más profundos y trascendentes, puede ser parangonable en el terreno de su propia praxis vital; en parte posibilitado por asociaciones emocionales e intuitivas conjuradas y brindadas por evocaciones de un simbolismo desplegado y habitualmente experimentado en su medio, enlazadas con comprobaciones también empírico-racionales; y en parte proporcionado -no lo olvidemos- por su interiorización mental de ese generador de sentido que es el esquema narrativo tradicional compartido. Un esquema que en lo sustancial homologa el personal relato experiencial de as da noite al de otros paisanos, y prefigura y estimula las evocaciones, sentidos e inteligibilidad, en suma, de la experiencia formalizada vía narración, así como la oportunidad contextual de su traída a colación en un relato que parcialmente variará según su edición e interlocutor, pero que será reconocible y dotado sentido para una audiencia local. Además, recordemos que detrás de la intención narrativa, incluso de temas tamañamente imaginarios como el de la compaña, es posible considerar maniobrando alguna concreta intentio auctoris, luego el entendimiento de sus implicaciones de sentido, aún parcial, es efectivo. Por ejemplo y llamativamente, cuando lo relatado se hace en tercera persona, presentando el relator como protagonista de la experiencia a un primo suyo, y nos brinda una historia distante, escéptica cuando no ironizante de lo acontecido y sus implicaciones sobre «mentalidades anticuadas» -aunque una historia a la vez receptora de algún poso de incertidumbre, visible en las apelaciones sobre la credibilidad de lo narrado-. Los pocos relatos que he recogido en la década de los ochenta ya son heterodiegéticos en este sentido. $\mathrm{O}$ cuando el relato se conoce sin estar argumentalmente habitado ya por nadie personalmente conocido, y el relator da por descontado su distanciamiento y expresa la falta de creencia en lo textualmente dicho -son contos da xente vella de entón-, pero domina aún con cierta perfección su tradicional esquema narrativo, lo valora acaso como un exponente "sociocéntrico" de identidad patrimonial local y lo brinda con cierto orgullo al forastero que se interesa por el tema.

VI. RETÓRICAS Y DESLIZAMIENTOS DIEGÉTICOS EN EL RELATO NATIVO Y EN LA NARRACIÓN AUTORAL

En otro orden, en De Antropologica Narratione (2006), Lisón describe en detalle cómo la voz del narrador-informante, por polisémica, es compleja en las múltiples funciones que trata de cumplir, como «yo» empírico, narrador extradiegético; 
como «yo» intradiegético, e incluso homodiegético (vividor de lo narrado); o como "yo»-testigo que saliendo, entrando y demorándose a veces en el umbral mismo entre el texto y la presencialidad externa, focaliza, juzga, argumenta e interpreta mediatizando interdiegéticamente. Atender a esta variedad de perfiles, ubicaciones y recursos retórico-expresivos (a los que habría que añadir el juego de referencias deícticas y determinantes que el relator también emplee) exige del investigador diferentes planos y estrategias de lectura de su relato y puesta en escena. Y es el modo como efectivamente interpreta las poliédricas dimensiones de sentido de la narración, una y otra vez. Esto hace que la interpretación antropológica urdida en la monografía, si constituye la expresión resultante de un momento dialógico intercultural, sin embargo no refleje exactamente lo que podría denominarse una homogénea "amalgama» de sentidos en la nueva expresión cultural intertextual vertida en su escrito, dadas las disonancias, lagunas de comprensión («eso que siempre se nos escapa") sobre todos y cada uno de los caminos del contexto comunicativo, carencias de sentido compartido, sobreentendidos, etc., que frecuentemente trufan la conversación.

Sin embargo, también podría aducirse que lo dicho para el narrador local puede redirigirse en los mismos términos para analizar la acción retórica y estrategias textuales de quien le interpreta; del narrador-escritor del texto monográfico (como ya hemos visto que el propio Lisón expresa). Y es que en su obra también Lisón, si bien pilota normalmente la narración en tercera persona, a menudo se desplaza o detiene su referencia autoral-actoral a través de los límites de la diégesis, en maniobras retórico-ilustrativas, como cuando se convierte en actor intradiegético en las ya aludidas pesquisas a las bruxas y corpos abertos tras haber llamado a su puerta, para inmediatamente resituarse en el habitual plano extradiegético donde nos habla describiendo y reflexionando sobre ellas en tercera persona (o cuando nos introduce a todos, en primera del plural, al ponderar esas constantes panhumanas que compartimos sobre la búsqueda de sentido, la experiencia de la enfermedad, la muerte o la renovación de la vida). Además, si la tónica es respetar fielmente el estilo directo, alguna vez parece completar la dicción o el pensamiento de los narradores convocados, abreviándola con sus palabras mediante un fugaz entrenzado de lo intra con lo extradiegético en una ambigüedad interdiegética que, probablemente, persigue otorgar flexibilidad interpretativo-expositiva al texto (así, Lisón, 1979: 103 y 194). No observo, empero, que recurra a la «ambigüedad narrativa", como ardid de imaginería literaria, tal como Lyons la define y propone para el repertorio retórico antropológico:

Brevemente, la ambiguedad narrativa representa la experiencia de una manera que difumina la distinción entre la conciencia del personaje y el narrador en tercera persona, por lo que es imposible determinar quién es el orador para un texto determinado (2001: 184).

Monumentos de la eficaz plasmación de los escenarios conversacionales y de la vibrante dinámica de la interacción dialógica, así como del análisis de la 
construcción del relato por parte de las especialistas rituales, de sus estrategias de sondeo, retiradas, dudas y amagos, y del propio papel -siempre lacónico- que el antropólogo juega en posibilitar ese análisis, son las dos sesiones adivinatorias con sendas carteiras, magistralmente llevadas y recogidas, que reproduce por extenso y en detalle (Lisón, 1979: 210-218). Es una demostración de la perfecta posibilidad de sintetizar una propuesta dialógica con el método interpretativo, que conjugue las expresiones en estilo directo con la narrativa autoral y el análisis que esta hace de las situaciones, razones y reflexiones de los actores en cada secuencia interactiva.

\section{EL PAPEL TRASCENDENTE DE LOS FRAGMENTOS TESTIMONIALES DE ESTILO DIRECTO EN LA HERMENÉUTICA ANTROPOLÓGICA DE LISÓN}

El recurso más querido por Lisón es, de todos modos, y como señalé, el de la convocatoria en profusión de fragmentos testimoniales localizados en estilo directo, como plurales reflejos que corroboran politéticamente los términos de su exégesis (si hemos de buscarle un sentido retórico). Esta reunión va mucho más allá del baladí connotado de "yo estuve allí», edificador de la clásica autoridad empírica del experto escritor de monografías, tan analizado por quienes han estudiado las retóricas antropológicas. En Lisón se trata más bien de hacer que «ellos -sus informantes, y narradores- estén aquín: que aún en tercera persona, sin referencia personal y sí locativa (lo más común), sin embargo, colonicen interdiegéticamente el texto con su polícroma multiplicidad de relatos experienciales, que dejan traslucir esquemas narrativos culturales. Ciertamente habrá habido una selección de textos convocados, pero es contrarrestado este sesgo por la densa diversidad de voces: en la confección de su narrativa monográfica, el autor se aparta brevemente, pero una y otra vez, para dejarles paso y de nuevo retomar el hilo analítico e interpretativo. Lo obrado resulta en que este interpolado no degenera en confusión e incertidumbre: los hipotextos orales alimentan el hipertexto monográfico, pero continúan allí, autónomos, reforzándose unos a otros.

Podría objetarse que este esmero lisoniano en convocar guardando las distancias puede provocar una objetivación o invención estereotípica de la cultura gallega, una esencialización colectivizadora, al dejar esos modos de sentir, razonar, obrar y narrar exclusivamente del lado, y en boca, de sus informantes aldeanos. Pero esto sólo sería así desde la miopía de ignorar el culminante esfuerzo generalizador acometido por la hermenéutica en todas sus monografías para sondear, manifestándose en los particularistas modos locales, universales pan-humanos: respuestas comunes, aunque sean culturalmente heteromórficas, que todos desplegamos para afrontar los grandes y graves enigmas, fenómenos, aprietos y menesteres que en este mundo a unos afectan y a otros también. Además, los motivos culturales estudiados no son abordados como estáticas esencias culturales, pues parte de estudios previos de la historicidad de cada uno de ellos, cristalizada, por 
ejemplo, en los fundamentos medievales de la ideología de la casa o en las tradiciones germánicas que preludian e informan el tema de la compaña.

Quizá el escrúpulo lisoniano por preservar literalmente la expresión del otro en las descripciones etnográficas pudiera encontrar una alternativa epistemológica, si constatamos que en realidad la comprensión ya ha de estar labrada principalmente en la mente del propio antropólogo que ha desarrollado el proceso etnográfico, más que en sus registros literales, pues si éstos complementan esa memoria comprensiva empíricamente desarrollada, el cuidado extremo de la literalidad de los registros y su acumulación también podrían estar aquejados de una cierta ritualidad -si no fetichismo- positivista. Y la comprensión debe anidar en la mente del investigador merced a la experiencia interactiva, dialogante y a la escucha, cuajada por ser largamente compartida sobre el terreno, de forma que es en esa consumada Verstehen personal donde prenda y fructifique la exégesis escrita, posiblemente más flexible y conscientemente autoral, sin complejos autoritarios ni literarios. Ciertamente las mejores herramientas del etnógrafo son su propia memoria y juicio, amueblados de las experiencias de campo, y la comprensión de los sentidos involucrados en sus escenarios y lances de interacción y diálogo. Ingold sugiere que esas personas que nos acogen y obsequian con sus relatos y comentarios no son informantes, sino nuestros maestros en el conocimiento local, y con ellos -con su convivencia- aprendemos. No los objetivamos, sino que nos acompañamos y nos "permitimos ser educados por ellos» (Ingold, 2020: 21), e incluso:

Se trata de recurrir a lo que aprendemos de nuestra educación con otras personas para especular sobre cuáles podrían ser las posibilidades y condiciones de vida. Creo que como antropólogos deberíamos apreciar esa libertad para especular, para decir lo que nosotros pensamos sin fingir que nuestras palabras son realmente destilaciones de las opiniones de los pueblos entre los cuales hemos realizado nuestros estudios. De hecho, si no hubiera sido por esos estudios, no diríamos las cosas que decimos. Pero no es a nosotros a quien corresponde hablar en defensa de nuestros maestros. Nosotros hablamos con nuestra cabeza y nuestro corazón, no con los de ellos, y sin duda es deshonesto aparentar lo contrario (2020: 111).

Sin embargo, y más allá de dudar de que sea competencia nuestra plantearnos "potencialidades" de la vida local, como pretende el citado autor, sino abordar su experiencia comunicable de la realidad efectiva, estimo que esa opción de Ingold corre el riesgo de abocar de facto a un abandono de la base empírica del conocimiento etnográfico de los fenómenos culturales en su realidad presente, y con él al silenciamiento del Otro y al escamoteo de referencias legibles sobre sus argumentos, experiencias personales, inquietudes y opiniones reales; aquellos que se afanan entusiásticamente en comunicarnos los relatores con sus andanzas expresivas a través de los límites de sus propias diégesis narrativas, por no decir ya el impedir la empatía con ellos. Es decir, el no convocar testimonios directos de nuestros relatores, sean maestros o informantes, ni hacerlo pródiga y sistemáticamente, al clausurar todas las ventanas que alumbren la etnografía para el 
lector, puede aplanar el texto monográfico y enmudecer la polifonía que le da densidad cultural, lo enriquece, e incluso permite relativizar extremos de la misma interpretación autoral, posibilitando a aquél acceder autónoma y críticamente a una vasta dimensión etnográfica, incomparablemente más fértil en posibilidades de cotejar y comprender sentidos y diversidad de estilos y usos culturales que cualquier monólogo autoral, aunque este ostente su carácter de hipertexto embebido de experiencias camperas. La convocatoria de "fragmentos narrativos en estilo directo" es uno de los factores que, afortunadamente, más «impurifican» la ficción monográfica al referirla a la realidad efectivamente vivida (cf. Sanmartin, 1995), consolidando así un género propiamente antropológico. Además, permitirá examinar la necesaria historicidad de los hechos culturales al poderlos comparar con narraciones de otras épocas. Más vale entonces abrir los vanos para que «ellos también estén aquí", en el escenario de la monografía publicada, y de hacerlo con capacidad de convocatoria. Y aunque eso suponga mantener la retórica del "ellos» frente al "nosotros», a la postre -y de ahí el sentido de la hermenéutica de Lisónnos será factible comprobar cómo en un ulterior y decisivo plano de interpretación el "Nosotros" ha de ampliarse hasta abarcar a los "otros" como copartícipes, desde uno de los modos -su modo- culturalmente reales y equivalentes, de la diversa y politética manifestación de lo humano.

\section{REFERENCIAS BIBLIOGRÁFICAS}

Clifford, J. y Marcus, G. E. (eds.). (1991). Retóricas de la Antropología. Madrid: Jucar.

Couceiro, E. (2020). Esquemas culturales y patrones narrativos. Cambios y permanencias en los relatos gallegos sobre el lobo. En H. Velasco (ed.), Maestro Lisón. Zaragoza: Fundación Lisón-Donald.

Dow, J. (1986). Universal Aspects of Symbolic Healing: A Theoretical Synthesis. American Anthropologist, 88.

Georges, R. A. (1969). Toward an Understanding of Storytelling Events. The Journal of American Folklore, 82, pp. 313-328.

Ingold, T. (2020). Antropología: ¿Por qué importa? Madrid: Alianza.

Lisón, C. (1973). Perfiles simbólico-morales de la cultura gallega. Madrid: Akal.

Lisón, C. (1979). Brujería, estructura social y simbolismo en Galicia. Madrid: Akal.

Lisón, C. (2004). La Santa Compaña. Fantasías reales. Realidades fantásticas. Madrid: Akal.

Lisón, C. (2006). De Antropológica Narratione». En C. Lisón (ed.), Antropología: horizontes narrativos. Madrid: CISC.

Lisón, C. (2012). Teoría etnográfica de Galicia. Madrid: Akal.

Lyons, T. (2001). "Ambiguous Narratives». Cultural Anthropology, 16.

Nadel, S. F. (2020 [1954]). Nupe Religion. Routledge: London.

Rabinow, P. (1992). Reflexiones sobre un trabajo de campo en Marruecos. Gijón: Júcar.

Sanmartin, R. (1995). De impura fictione. En C. Lisón, (comp.), Antropología y Literatura. Zaragoza: Gobierno de Aragón.

Turner, V. (1999). La selva de los símbolos: Madrid: Siglo XXI.

Wilson, M. (1954). Nyakiusa Ritual Symbolism. American Anthropologist, 56. 
